\title{
Message from the Editors
}

The South African Journal of Plastic \& Reconstructive Aesthetic Surgery \& Burns is the first journal in South Africa (SA) for plastic surgery, and the first for burns. The journal intends to support all authors in publishing, to strengthen academics in South Africa (SA).

We do encourage contributions from everyone involved in plastic surgery and in burns. Dr Chris Snijman, past president of the Association of Plastic, Reconstructive and Aesthetic Surgeons of Southern Africa (APRASSA), endorsed the journal before the end of his term in September 2018. The journal is also endorsed by the newly formed SA Burn Association, and is its official publication vehicle.
As president of the College of Plastic Surgeons of $\mathrm{SA}$, this educational, peer-reviewed journal is welcomed. We have to start somewhere, and with this first issue we have made some baby steps, and look forward to rapid growth of the journal. Best regards,

\section{Wayne Kleintjes}

Editor-in Chief

waynekleintjes@yahoo.com

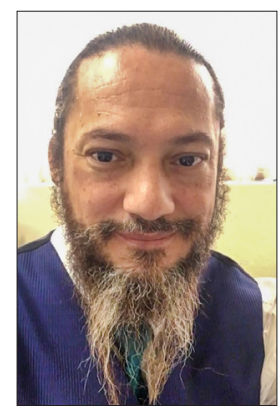

